\title{
WILDFIRE INDUCED DEGRADATION OF WOODY VEGETATION IN DRY ZONE OF KAZAKHSTAN
}

\author{
Alexey Terekhov \\ Kazakh Research Institute of Ecology and Climate, Ministry of Environment, KAZAKHSTAN \\ E-mail: aterekhov1@yandex.ru
}

Commission VIII, WG VIII/6

\begin{abstract}
:
Small bushy tree species dominate the semi-arid areas of Kazakhstan. In the course of their life cycle, they form a layer of litter that is resistant to wind transport. This small shrub species with its own litter play a significant role in the spectral characteristics of the Earth surface. Changes in the density of shrub canopy forms or replacing them with herbaceous species is accompanied by significant changes in the spectral characteristics in the visible and near infrared spectral bands in the autumn. These changes can be recorded from satellite data. LANDSAT-TM images during 1985-2007 years and MODIS data (USGS: MOD09Q1, 2000-2010) used to diagnose changes in relation between woodylherbaceous vegetation species in the dry zone of Kazakhstan. It was found that over the past 10 years, spreading small shrub forms of semi-arid vegetation significantly decreased. There is a persistent expansion of herbal forms, leading to the semisteppe formation areas. The mechanism of repression of wood forms constructed through the accumulation of dry plant mass during wet years, with its subsequent burnout during wildfires. In the case of a strong fire, a complete destruction of species is observed. The restoration of small shrub cover demands more than 20 years. Comparative analysis of LANDSAT-TM images showed a 10 times increasing of the fire scar areas in the test area in the central part of Kazakhstan between 1985 and 2007. According MOD09Q1 was conducted mapping small shrub forms of degradation in Kazakhstan. Reducing the area occupied by woody vegetation, semi-desert was about 30 million hectares or over $30 \%$ of their total range in Kazakhstan.
\end{abstract}

